\title{
ANÁLISE ESTRATÉGICA DO ECOMARKETING E SEUS DESAFIOS EM EMPRESAS DE DIVERSOS SETORES PRODUTIVOS
}

\author{
Maria Dayana Santos Oliveira (URCA) marsantosoliv@gmail.com
}

\begin{abstract}
Resumo
Este artigo teve como principal objetivo analisar e abordar a temática do Ecomarketing e seus desafios enfrentados para ser uma ferramenta estratégica que as empresas utilizam na obtenção de transmitir uma imagem ecologicamente correta de seus produtos e assim proporcionar vantagens competitivas com outras entidades. Reforçou a importância de se implantar um bom ecomarketing e destacou a exigência dos consumidores em querer produtos de sumo sustentável destacando a atual necessidade cada vez mais crescente nos clientes na compra de um produto ou serviço, que mais uma vez passou a testar a capacidade das empresas de se adaptar e atender as suas necessidades. Apresentou algumas empresas que atuam de forma sustentável utilizado de maneira ética e sem abuso de poder, procurando meios de conquistar a fidelidade do consumidor junto as organizações. Verificou-se que o marketing verde está se tornando uma importante ferramenta mercadológica pois muitas organizações procuram a cada dia ter um bom diferencial competitivo para se destacar perante os seus concorrentes, independente do mercado em que a organização atua. $\mathrm{O}$ maior desafio das empresas é provar para os consumidores que suas ações são verdadeiramente ecológicas e corretas.
\end{abstract}

Palavras-Chave: Ecomarketing, Greenwashing, Rotulo Ecológico.

\section{Introdução}

A meados do século XX a AMA (American Marketing Association) promoveu um Workshop com intuito de promover uma discussão relacionando o impacto do marketing sobre o meio ambiente. Surgiu então um tipo de marketing voltado a sustentabilidade afim de proporcionar seus mais novos conceitos, veio mostrar que o mercado necessitava de produtos de uso ecológico, então passou a chamar esse mais novo conceito de marketing verde, ambiental ou ecomarketing. (Botelho \& Manolescu, 2010; Rego et al,2016)

Em virtude do aumento gradativo das populações ocorreu aumento na produção e o consumo de bens e serviços, os danos provocados por essas atividades tiveram como consequência a exploração, o desmatamento, poluição, destruição do habitat e acumulo de resíduos gerando impactos ao meio ambiente de forma que ocorreu esgotamento de recursos não renováveis, extinção de espécies, afetando a qualidade de vida dos seres vivos e comprometendo a sobrevivência das gerações futuras. (Miranda et al ,2016)

Sendo assim, algumas empresas vêm dotando formas de oferecer ao consumidor produtos de consumo consciente que satisfaçam seus desejos e necessidades, dando aos consumidores preferencias de produtos ecológicos dando o mínimo de impacto negativo sobre a natureza e a sociedade. (Prado et al,2011). 
No entanto, algumas corporações alegam uma atuação benéfica ao meio ambiente, mas de fato mente com relação a descrição de seus rótulos, uma prática que pouco a pouco tornou-se corriqueira, despertando desconfiança em seus consumidores tal fato se denomina como greenwashing. De acordo com Idec - Instituto Brasileiro de Defesa do Consumidor (2020) realizou um levantamento com mais de 500 embalagens de produtos dos maiores supermercados do Brasil, com intuito de mostrar as práticas do greenwashing e analisar algumas marcas oriundas de empresas com falsas certificações ambientais, foi comprovado que apenas $52 \%$ não era greenwashing e $48 \%$ era greenwashing.

Esse trabalho teve como principal objetivo analisar e abordar a temática do Ecomarketing e seus desafios enfrentados para ser uma ferramenta estratégica que as empresas utilizam na obtenção de transmitir uma imagem ecologicamente correta de seus produtos e assim proporcionar vantagens competitivas com outras empresas.

\section{Referencial teórico}

De acordo com Botelho \& Manolescu (2010) marketing ambiental é uma ferramenta de planejamento estratégico de diversos processos de elaboração. Estimula a elaboração, produção, entrega ao cliente e o descarte do produto, sendo de forma sustentável no qual se utiliza de maneira ética e sem abuso. Se deve à globalização no desenvolvimento de novas tecnologias a medida que os obstáculos comerciais diminuíam, as relações comerciais ganharam intensidade e os mercados globais se expandiram, houve então a necessidade de implementar uma ferramenta que proporcionasse mudanças, atendendo os princípios ecológicos, econômicos, sociais e culturais. Tal fato a definição para marketing verde frente as organizações é a maneira de estar conscientizando a população a consumir ecologicamente produtos que não afetem tanto o meio ambiente. Sua estratégia é voltada ao processo de venda de produtos e serviços que são baseados na obtenção que beneficie os consumidores, as

empresas e o meio ambiente. É a estratégia que trata a vinculação do modo de produção, ou da postura em geral da empresa em relação ao produto, marca ou serviço para transmitir aos consumidores uma imagem ecologicamente consciente e sustentável.

É uma ferramenta voltada ao processo de venda de imagem de forma a agregar valores aos produtos e serviços, onde é apresentado aos consumidores propagandas publicitarias de forma a incentivar aos consumidores a respeitar o meio ambiente e possivelmente valorizar a empresa que está adotando práticas sustentáveis. Segundo Xavier \& Chiconatto (2014, p.3), “...o marketing verde incorpora uma ampla gama de atividades, incluindo a modificação de produtos, alterações de processos de produção, mudanças de embalagem, bem como a 
alteração da publicidade".

Greenwashing conhecida também como lavagem a verde é uma palavra que vem sendo usado por ambientalistas para nomear responsabilidade ambiental a empresas que não passam de ações de marketing não vinculadas à estratégia do negócio. É empregada por empresas, organizações e governos afim de promover com o apoio da área do marketing e relações públicas iniciativas enganosas de sustentabilidade ecológica um ato malicioso de aumentar a importância de fatos irrelevantes e disfarçar uma fraca atuação ambiental. É uma estratégia que serve tanto para vender falsa sustentabilidade ao consumidor como para esconder ações que de certa forma cheguem a agredir o meio ambiente. Há cada vez mais conscientização e preocupação, por parte da sociedade, com a agressão à natureza e isso se reflete diretamente nas escolhas de compra de muitos consumidores. Um fato simples para ajudar a identificar as práticas ocorridas pelas empresas é saber o que a organização diz, mostra, faz e vende relacionando aos impactos que ela pode causar na operação de seu negócio. (Mena,2017; Pagotto,2017)

O processo de rotulagem ecológica é definido de acordo com as normas do ABNT, é uma certificação voluntária de produtos e serviços, desenvolvido de acordo com NBR ISO 14020, NBR ISSO 14021, NBR ISO 14024 e NBR ISSO 14025 (Gomes \& Junior,2018). Segundo o Portal da Sustentabilidade (2020) a rotulagem ambiental é uma importante ferramenta de comunicação entre as empresas, autoridades públicas e consumidores, promovendo a inovação no desenvolvimento tecnológico, gestão e marketing, objetivando a proteção do meio ambiente e atuando no aumento da conscientização dos consumidores. Os benéficos quando se enquadra um selo verde é promover a redução de desperdícios assim otimizando os processos; apresentar ao mercado que sua empresa se preocupada com as próximas gerações; incentivar a preservação do meio ambiente, através da diminuição dos impactos negativos permitindo o enquadramento nas exigências de propostas sustentáveis.

\section{Metodologia}

Este artigo foi elaborado a partir de revisões bibliográficas, nas quais as informações foram coletadas na base do Google acadêmico, páginas de empresas e em sites: de revistas, portais e organizações especializadas na temática, como também, os trabalhos utilizados para o estudo foram selecionados de acordo com os métodos e resultados relacionados ao tema em questão. Foram escolhidos oito artigos bibliográficos e seis relatórios empresariais do ramo industrial, comercial e de serviço, com base nessa seleção, foi feito análises e levantamento de dados que caracterizaram o possível entendimento da implementação do ecomarketing nas empresas e o 
fator que visionou os olhares dos consumidores, além disso, foram mostrados alguns exemplos de empresas que trabalham e colocam em pratica o marketing verde, visando o fortalecimento da marca, criando projetos e ações que incentive as pessoas a usar seus produtos de formas sustentáveis.

\section{Resultados e discussões}

Proporcionar a criação de ações apoiando as causas ambientais no mercado atual diferencia empresas preocupadas e não preocupadas com o meio ambiente. Marcas que tentam mostrar apelos ecológicos focalizando um consumo consciente é extremamente poderosa, pois com o uso do ecomarketing apresentam questões com intuito de conquistar o cliente. As organizações devem não só se prender a questão de vender seus produtos e serviços, mais apoiar causas ambientais, onde apresentem novas formas de obter produtos de uso consciente sem prejudicar tanto a natureza na extração de seus recursos, ou seja, substituir substancias por outras que gerem menos impacto e não altere o ingrediente do produto. Sendo assim seguem um modelo básico mostrado na figura-1, levando os indivíduos a atuarem em conjunto e de forma sustentável que estabeleçam dimensões sustentáveis onde satisfaçam as necessidades básicas, propagando a solidariedade com as gerações futuras e incentivando a participação da população envolvida a preservar os recursos naturais e o meio ambiente, onde ocorra a elaboração de um sistema social que garanta emprego, segurança social e respeito a outras culturas.

Figura 1 - Dimensões da sustentabilidade.

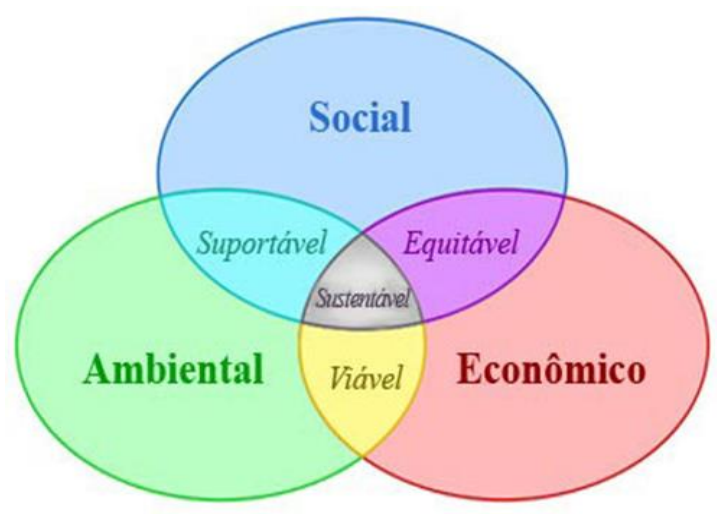

Fonte: https://www.portalgsa.com/sustentabilidade.htm(2019)

Com o crescimento e utilização dos novos meios tecnológicos, cada vez mais as pessoas tomam consciência dos danos causados ao planeta e a sociedade em geral, a sociedade define apoiar e lutar por causas que enfatizam a preservação do meio ambiente e forçam de uma forma ou de outra as empresas há adotarem medidas ecológicas que possam mudar a situação 
já que o consumismo move o mundo. Visto isso o ecomarketing inspira e aprimora seus produtos, na medida em que os profissionais se inovam para melhorar a posição no mercado, gerando demanda, o que, por sua vez, cria postos de trabalho contribuindo com os resultados financeiros da empresa, também permite que as empresas se envolvam de forma mais sólida em atividades socialmente responsáveis. Os profissionais se envolvem na gestão da troca de diferentes tipos de produtos: bens, serviços, eventos, experiências, pessoas, lugares, propriedades, organizações, informações e ideias. Onde devem decidir quais recursos projetar em seus produtos, estipulando preços, onde vender bens ou oferecer serviços e quanto gastar com propaganda, vendas, Internet e marketing digital. Essas decisões devem ser tomadas em um ambiente fomentado pela Internet, onde consumidores, concorrência, tecnologia e forças econômicas mudam rapidamente, e as consequências do que os profissionais dizem ou fazem podem se multiplicar instantaneamente. Visto isso o marketing verde possui três tipos importantes que relaciona marca do produto em avaliar seus meios internos e externos pode definir o ritmo do crescimento da instituição ou mesmo a permanecia da marca no mercado consumista: Reputação de uma marca é totalmente valiosa no mercado, pois para ocorrer mudanças em quem possivelmente se destacar melhor entre suas concorrentes, seus aspectos podem fazer com que as empresas cresçam engajadas as causas verdes mesmo aos olhos de quem nunca pensou no consumo consciente e também fazer com que decresça ao seguir o caminho contrário. Assim sendo, adotar uma estratégia de marketing verde é acima de tudo uma segurança que pode ser gerenciada para se tornar um ponto de apoio no crescimento de uma empresa; Aceitação no mercado internacional é padronizar seus produtos e planejar ações para tornar a marca conhecida do público local definindo assim as melhores possibilidades para a expansão internacional. Sendo assim a marcar que quiser se destacar fora do seu país de origem vai encontrar diversas barreiras de aceitação por isso é importante utilizar métodos que renove sempre a produção e a escolha da matéria-prima pois será de suma importância nesse processo. No entanto, nesse grande panorama global onde há fortes mudanças no planeta, os produtos devem atender aos meios sustentáveis. Portanto uma empresa que adota uma estratégia de Marketing verde tem um alcance de público internacional muito mais amplo; E perspectiva de longo prazo é o resultado que as marcas adotam o uso do Marketing verde têm mais tempo para se adaptar às mudanças e liderar um mercado. Dessa forma, passam a utilizar e a aprender técnicas que em algum momento vão ser as únicas aceitas no mercado. As empresas que começarem a buscar meios de cuidar e fazer com que a sociedade consumidora preserve o meio ambiente, estarão ganhando vantagens diante do mercado competitivo e se mostrando como inovadoras e bem vistas aos 
olhos dos seus consumidores.

A seguir será citado algumas empresas que adotam práticas sustentáveis, visando a redução dos custos de produção e do valor final dos produtos e, principalmente, para o fortalecimento da marca. Relacionado por apelo ecológico para as comunidades futuras, sobre como tomar medidas para melhorar a qualidade de vida com um mundo mais verde. Trazendo esse conceito para a realidade das pequenas, médias e grandes empresas, podemos dizer que é possível adotar a causa da preservação da natureza, da responsabilidade ambiental e adotar ao Marketing Verde sem ter que dispor de grandes investimentos. Existem muitas formas de uma empresa ajudar na preservação do meio ambiente, se beneficiar do marketing verde e, ainda, ampliar seus lucros, seja qual for o seu porte, segmento ou localidade.

Na figura-2 abaixo podemos ver que os dados percentuais apresentam analises que não se diferenciem tanto entre si, fato este que pode levar os consumidores a adotar um comportamento inativo, ou seja, pode trazer ao pensamento e a percepção do consumidor de que essas empresas são todas iguais, que buscam os mesmos objetivos falando sempre a mesma linguagem, logo, não se diferenciam em nada em relação às demais que estão no mercado. Sendo assim, o mapa perceptual apresenta um conjunto de empresas que apresentam a mesmas características ou o mesmo perfil considerado, demostrando atividades diversas, mas que utilizam os mesmos apelos ecológicos.

Figura 2 - mapa de percentual, considerando as empresas com apelos ecológicos

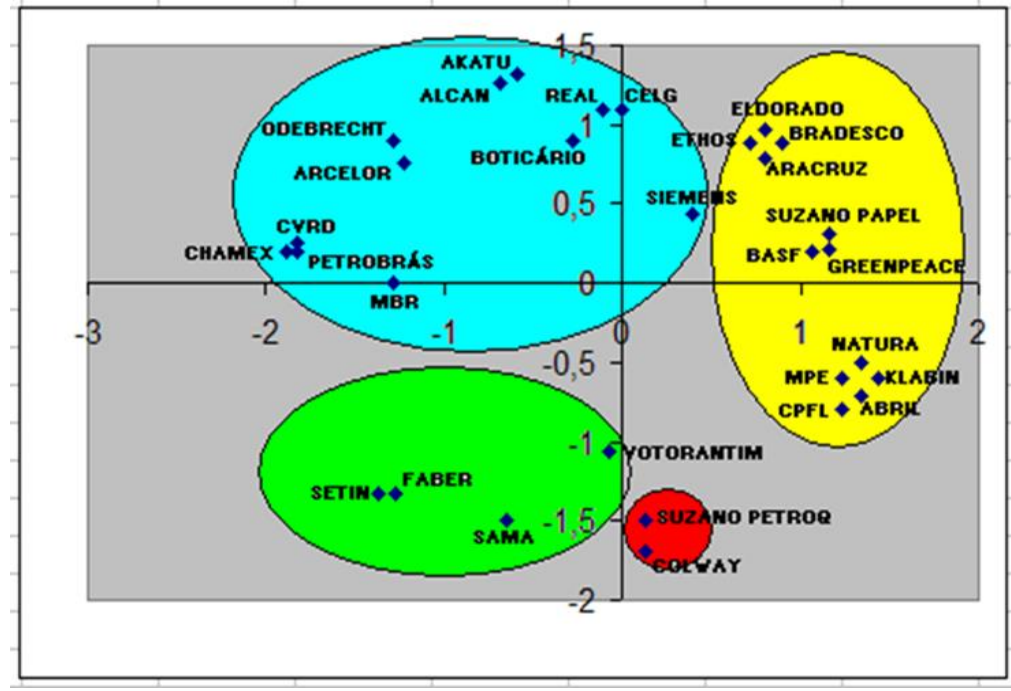

Fonte: comciencia.br (2012)

Grandes empresas têm adotado um papel de divulgação de causas ecológicas atingindo uma grande visibilidade no mercado. Além disso, prestam um forte investimento em políticas ecológicas e no desenvolvimento de tecnologias eco sustentáveis, trazendo para si uma 
imagem de inovação e respeito ao meio ambiente.

- Natura: em 2000, a empresa lançou a linha Ekos, com produtos que utilizam princípios ativos extraídos da biodiversidade nacional, de maneira totalmente sustentável sua campanha de sustentabilidade incorpora à vida de seus clientes no engajamento com o uso sustentável dos produtos usando uma estratégia para a redução de custos, se destaca também na criação de projetos de reflorestamento e de uso de energia renovável e o projeto Carbono Neutro um programa responsável por reduzir emissões de gases do efeito estufa (GEE) onde houve uma redução em 2011 de 33\%. Priorizando, como parte da gestão sustentável de resíduos, os processos de reciclagem, incluindo o pós-consumo, e ainda implementando novas políticas de redução do consumo de água e energia em suas unidades;

- Bradesco: busca inserir a sustentabilidade em seus negócios com o objetivo de aumentar seu desenvolvimento ao longo prazo diante de um ambiente competitivo e dinâmico. Caminhando em direção à uma nova economia que leva a incorporar aspectos sociais e ambientais na gestão de riscos e de oportunidades para garantir resultados positivos e gerar valor compartilhado. O setor financeiro tem um papel importante na transição de uma economia verde e de baixo carbono, possuindo produtos e serviços específicos de acompanhamento especifico para auxiliar na evolução dos setores da economia verde em portfólio. Também participam de discussões e grupos empresariais, como o CEBDS, Febraban, Pacto Global, entre outros, com vistas a contribuir com o desenvolvimento de metodologias, elaboração de estudos e levantamento e análise de informações. Em 2017, houve um relevante avanço nos estudos Mensuração de recursos financeiros alocados na Economia Verde, Financiamento da Recomposição Florestal, Gestão do risco de desmatamento, desenvolvidos pela Febraban. Esses trabalhos contribuem na identificação de oportunidades de negócios e na gestão do risco socioambiental (inclusive no que se refere ao aspecto climático). Também gera subsídios para dialogar com governos a fim de incentivar a criação de políticas públicas para transição rumo à economia verde;

- Ypê: busca atuar junto ao meio ambiente e ao meio social, a construção de um mundo melhor. Iniciou um projeto junto a fundação SOS Mata Atlântica uma organização não-governamental que defende os remanescentes da Mata Atlântica esse projeto tem um intuito de fazer o reflorestamento de áreas devastadas pelo ser humano. O projeto faz parte do Programa Florestas do Futuro e têm desdobramentos sociais pois, por meio do projeto, são gerados empregos diretos, além da comunidade envolvida com as 
atividades também ser beneficiada com educação ambiental, estimulando ações para o desenvolvimento sustentável e o exercício da cidadania. Em 2016 cerca de 600 mil arvores foram plantadas em diversas regiões. Seus produtos de limpeza de alto desempenho, práticos, sustentáveis e acessíveis produzindo embalagens com menor quantidade de matéria-prima, utilizando material reciclado na sua composição e passíveis de reciclagem, optando por tecnologias que minimizem a geração de resíduos e que permita a reutilização;

- Boticário: A Fundação Grupo Boticário de Proteção à Natureza, principal expressão do investimento social privado de nosso Grupo, nasceu em 1990 para contribuir com a conservação da natureza do Brasil. Em 2015, ao completar 25 anos, chegou a 1.457 iniciativas apoiadas em todos os biomas do país e no ecossistema marinho. A instituição mantém duas Reservas Particulares do Patrimônio Natural, por meio das quais protege mais de 11 mil hectares dos dois biomas mais ameaçados do Brasil: Mata Atlântica (Reserva Natural Salto Morato, em Guaraqueçaba, nosso quadro funcional é composto por cerca de 7 mil colaboradores diretos de diferentes idades, etnias, culturas, graus de escolaridade, condições físicas e intelectuais. No Grupo, $100 \%$ deles são beneficiados pelas convenções coletivas de trabalho dos municípios em que estão alocados, considerando estruturas operacionais litoral do Paraná) e Cerrado (Reserva Natural Serra do Tombador, em Cavalcante, interior do Goiás). Suas ações incluem, também, apoio a projetos de outras organizações, investimento em estratégias inovadoras de conservação, como pagamento por serviços ambientais, a disseminação do conhecimento e a sensibilização da sociedade para a causa;

- Unilever: O Plano de Sustentabilidade da Unilever busca três resultados significativos: Ajudar mais de 1 bilhão de pessoas a tomar iniciativas para melhorar sua saúde e bem-estar; vincular seu crescimento à redução do impacto ambiental, obtendo reduções absolutas durante a vida útil de seus produtos. A meta é reduzir pela metade a pegada ambiental da fabricação e da utilização dos produtos; melhorar as condições de vida e trabalho de pessoas que fazem parte da cadeia de fornecimento. Com relação ao meio ambiente, a Unilever vai se concentrar na redução dos gases de efeito estufa, no melhor aproveitamento da água, no tratamento dos resíduos e em recursos agrícolas sustentáveis. As Metas do Plano é melhorar a saúde e o bem-estar, reduzir o impacto ambiental e melhorar as condições de vida e trabalho;

- Braskem: analisa de forma objetiva a sua estratégia de sustentabilidade, baseada em três pilares: Processos e recursos cada vez mais sustentáveis; Portfólio de produtos 
cada vez mais sustentável; Soluções para que a sociedade tenha uma vida cada vez mais sustentável. Desde sua fundação, buscam alinhar estratégias de crescimento à processos e ações que minimizem eventuais impactos ambientais e sociais. Com foco no desenvolvimento de uma estratégia de sustentabilidade, trabalham com dez macro objetivos e metas definidas para 2020 - todas atreladas aos 17 Objetivos do Desenvolvimento Sustentável (ODS) da ONU. Relacionam-se com esses pilares que incluem os temas materiais para a empresa e suas partes interessadas. Para cada macro objetivo, foram definidas metas estratégicas para 2020 e ações intermediárias para que eles sejam alcançados. Em 2017, foi atingida uma meta antecipada em dois itens bastante relevantes para o cenário ambiental atual: Eficiência Hídrica e Mudança Climática. A Braskem acredita que integridade e segurança são a essência de uma empresa de valor, competitiva e bem-sucedida. Estes princípios garantem a perpetuidade do negócio e de sua reputação no mercado.

Como vimos, a preocupação com as causas relacionadas à preservação do meio ambiente está a cada dia mais presente na vida dos brasileiros. E no futuro fará parte do senso comum da população.

\section{Considerações finais}

A maneira como o marketing verde veem tomando espaço nas pequenas e grandes empresas é de fundamental importância pois proporciona a marca do produto um índice de desenvolvimento sustentável, atingindo uma grande visibilidade no mercado e incentivando aos consumidores de utilizarem de seus produtos de forma sustentável. Dessa forma prestam um forte investimento em políticas ecológicas e proporcionam o desenvolvimento de tecnologias eco sustentáveis, afim de gerar uma reputação positiva em relação a gestão ambiental e o poder de atrair novos consumidores, além de atribuir mais valor ao posicionamento da empresa diante da sociedade. E pensando a longo prazo, deve saber o que é Marketing Verde e colocá-lo efetivamente em prática, futuramente, será não apenas um diferencial para as empresas, mas uma postura mais que necessária. Quando você faz bem ao meio ambiente, as boas ações são convertidas em reconhecimento e, com isso, suas vendas podem até aumentar.

O planejamento e o uso estratégico do marketing são de suma importância, pois, ajuda e incentiva a comunidade a consumir seus produtos e ensina como usá-los. Em primeiro lugar, vale a pena pensar em tornar as atividades da empresa ligadas ao princípio de reduzir os impactos ambientais prejudiciais e preservar o meio ambiente. Algumas iniciativas comuns 
para implementação é investir e proporcionar atividades de reciclagem, reutilizar água da produção e dependências da empresa assim evita o desperdício, separar o lixo e dá um destino correto de forma adequada, apresentar e ampliar programas que estimule a redução da degradação ambiental e pensar em maneiras de aumentar a durabilidade de seus produtos. Essas diretrizes e ações direcionadas a cultura de produção e gestão da empresa, é o ponto inicial para praticar o ecomarketing.

\section{Referências}

ABNT Certificadora. 2020. Disponível em: < https://www.abntonline.com.br/sustentabilidade / > Acesso em: 13 abr. 2020.

BOTELHO, Júlio Cezar \& MANOLESCU, Friedhilde Maria Kustner, (2010). O MARKETING VERDE COMO DIFERENCIAL COMPETITIVO NAS ORGANIZAÇÕES. XIV Encontro Latino Americano de Iniciação Científica e X Encontro Latino Americano de Pós-Graduação - Universidade do Vale do Paraíba, 0105 .

GIL, Antônio Carlos. Como Elaborar Projetos de Pesquisa. 4. ed. - São Paulo: Atlas, 2002.

GOMES, Nivaldo Simões; JUNIOR, Eloy Fassi Casagrande, (2018). Rotulagem Ambiental de Produtos: uma análise de 14 programas do mercado brasileiro, sob o olhar do consumidor. RG\&SA - Revista Gestão e Sustentabilidade Ambiental, Florianópolis, v. 7, n. 1, p. 614-642, jan./mar. 2018.

GSA, Sustentabilidade e Meio ambiente. Disponível em: < http://www.portalgsa.com/sustentabilidade.htm > Acesso em 26 mai.19.

Idec - Instituto Brasileiro de Defesa do Consumidor. 2020. Disponível em: < https://idec.org.br/greenwashing/pesquisa > Acesso em: 13 abr. 2020.

Marketing Verde e a Propaganda Ecológica - 2012. < http://www.comciencia.br >Acesso em: 23 mai. 2019.

MENA, Isabela. Verbete Draft: o que é greenwashing. 27 Set. 2017. Disponível em:

<https://www.projetodraft.com/verbete-draft-o-que-e-greenwashing/> Acesso em: 13 abr.2020.

MIRANDA, Amanda; Klepa, Rogerio; Santana, José; Filho, Silvério. Marketing Verde: Sua aplicação e o real compromisso das empresas com o meio ambiente. 30 de setembro de 2016. Disponível em:

<http://www.inovarse.org/sites/default/files/T16_082.pdf > Acesso em: 13 de abr. 2020.

PAGOTTO, Erinco. "Greenwashing” e os conflitos éticos da propaganda ambiental. 25 mai. 2017. Disponível em: <https://www.nexojornal.com.br/academico/2017/05/25/Greenwashing-e-os-conflitos\%C3\%A9ticos-da-propaganda-ambiental> Acesso em: 13 abr. 2020.

PRADO, Rejane Alexandrina Domingues Pereira do; SILVA, Marli Auxiliadora da; JUNQUEIRA, Maíra Cinquini; ALMEIDA, Lia Noronha Nunes, (2011). A influência do marketing verde nos hábitos de consumo dos jovens universitários dos cursos de administração: estudo em instituições de ensino superior (IES). REMark - Revista Brasileira de Marketing, São Paulo, v. 10, n. 2, p 126-145, mai./ago. 2011.

REGO, Klivia Feitosa; OLIVEIRA, Tiago Augusto dos Santos; BATISTA, Clecia da Conceição; BARROS, Tiago Lima; MELO, Jamylle dos Santos. O marketing verde como ferramenta para aumentar a vantagem competitiva das organizações. XXXVI ENCONTRO NACIONAL DE ENGENHARIA DE PRODUCÃO. 06 de outubro de 2016. Disponível em: 〈http://www.abepro.org.br/biblioteca/TN_STO_230_346_29949.pdf > Acesso em: 13 abr. 2020.

Relatório Anual - 2017. Disponível em: < https://www.braskem.com.br/Portal/Principal/arquivos/relatorioanual/2017/2018-07-10-RAS2017-Braskem-PDF-interativo-portugues.pdf > Acesso em: 02 jun. 2019. 
Relatório de Progresso - 2016. Disponível em: < https://www.unilever.com.br/Images/relatorio-de-progresso2016-portugues tcm1284-510366_pt.pdf > Acesso em: 02 jun. 2019.

Relatório de Sustentabilidade - 2015. Disponível em: 〈https://relatoweb.com.br/boticario/15/downloads.php $>$ Acesso em: 02 jun. 2019.

Relatório Integrado - 2017. Disponível em: < https://relatoweb.com.br/bradesco/2017/pt/sustentabilidade.html > Acesso em: 02 jun. 2019.

Relatório Programa Florestas do Futuro - Parceria Química Amparo / Ypê - 2014. Disponível em:

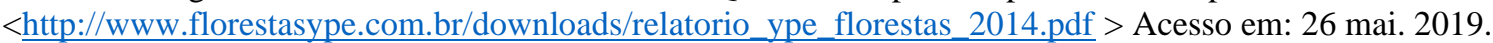

Relatório Anual Natura - 2008.Disponível em:

$<$ https://natu.infoinvest.com.br/ptb/3670/relatorio20anual202008 versao20completa20revista_0906_FINAL.pdf

$>$ Acesso em 26 mai. 19.

XAVIER, Rodrigo Navarro; CHICONATTO, Patrícia, (2014). O rumo do marketing verde nas organizações: conceito, oportunidades e limitações. Revista Capital Científico - Eletrônica, Jan/Mar 12(1),1-14. 